\title{
Imagen de la práctica de lactancia materna a través de la numismática Contemporánea
}

\section{Image of breastfeeding practice through modern coins \\ Imagem da prática do aleitamento materno através de numismática contemporânea}

\author{
Juan Francisco Reyes Revuelta \\ ${ }^{1}$ Diplomado en Enfermería y Profesor Asociado en la Escuela Universitaria de Enfermería de la Excma. Diputación Provincial \\ de Málaga. Universidad de Málaga \\ Cómo citar este artículo en edición digital: Reyes Revuelta, J.F. (2015). Imagen de la lactancia materna a través de la numismá- \\ tica contemporánea. Cultura de los Cuidados (Edición digital) 19, 41. \\ Disponible en: http://dx.doi.org/10.14198/cuid.2015.41.10> \\ Correspondencia: Centro Universitario de Enfermería de la Excma. Diputación Provincial de Málaga. \\ Plaza Hospital Civil S/N. C.P. 29011. Málaga. \\ Correo electrónico: reyesrevuelta@hotmail.com \\ Recibido: 11/12//2014; Aceptado: 7/03/2015
}

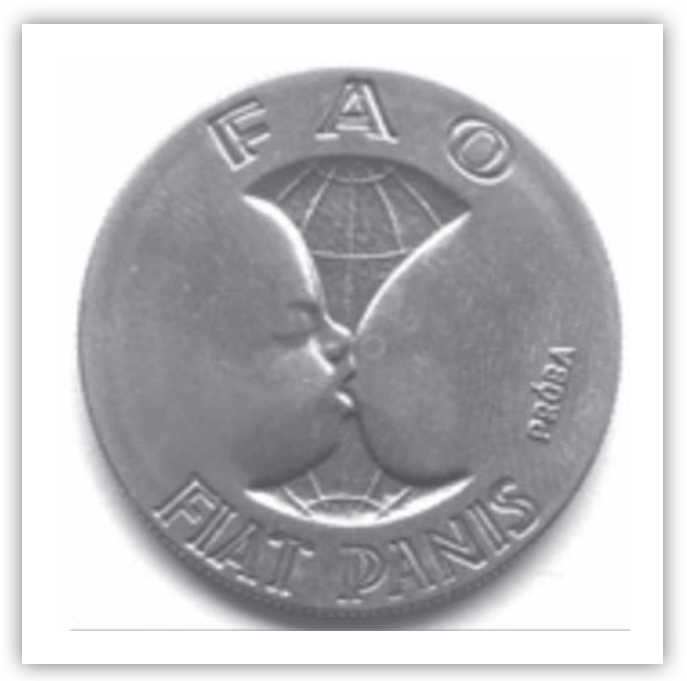

\section{ABSTRACT}

Numismatics is the hobby and art of collecting coins and banknotes from different eras and cultures. The reasons minted in various currencies allow us to know historical facts, empires, monarchs, evolution of art, customs and even allow us to display care related phenomena. This paper attempts to locate and identify world coins with images related to the practice of breastfeeding minted from 1900 to 2013 and its subsequent analysis us- ing iconographic methodology. The currencies behave like an interesting and original source of study, yet to be discovered in its entirety, for the construction of the History of the Care and Nursing.

Keywords: Iconography, Breastfeeding, Care history, Numismatics.

\section{RESUMEN}

La Numismática es la afición y el arte de coleccionar monedas y billetes de distintas épocas y culturas. Los motivos acuñados en las distintas monedas nos permiten conocer hechos históricos, imperios, monarcas, evolución del arte, de las costumbres e incluso nos permiten visualizar fenómenos relacionados con el cuidado. El presente trabajo trata de localizar e identificar monedas mundiales con imágenes relacionadas con la práctica de la lactancia materna acuñadas desde el año 1900 al 2013 y su posterior análisis aplicando la metodología iconográfica. Las monedas se comportan como una interesante y original fuente de estudio, aún por descubrir en su totalidad, para la construcción de la Historia de los Cuidados y de la Enfermería. 
Palabras claves: Iconografía, Lactancia materna, Historia de los Cuidados, Numismática.

\section{RESUMO}

Numismática é o hobby e arte de colecionar moedas e notas de diferentes épocas e culturas. As razões cunhadas em moedas nos permitem saber fatos históricos, impérios, monarcas, evolução da arte, costumes e até mesmo nos permitem ver fenômenos relacionados aos cuidados. Este trabalho tenta localizar e identificar moedas do mundo com imagens relacionadas à prática do aleitamento materno cunhadas desde o ano de 1900 para 2013 e sua posterior análise, aplicando a metodologia iconográfica. As moedas se comportam como uma fonte interessante e original de estudo, ainda a ser descoberto em sua totalidade, para a construção da História dos cuidados e Enfermagem.

Palavras-chave: Iconografia, Aleitamento materno, História dos cuidados, Numismática.

\section{INTRODUCCION}

Según el diccionario de la lengua española (2012) una moneda es una pieza de un material resistente, de peso y composición uniforme, normalmente de metal, acuñado en forma de disco y con los distintivos elegidos por la autoridad emisora, que se emplea como medida de cambio por su valor legal o intrínseco y como unidad de cuenta.

La numismática o "el arte de coleccionar y estudiar las monedas" es conocida desde los tiempos del imperio romano. La numismática como ciencia comienza tímidamente en el siglo XIX. Esta ciencia puede dar testimonio inestimable de la realidad política, geográfica, cultural y social de cada época y de cada país. A través del tiempo las colecciones temáticas han ido adquiriendo importancia documental y la numismática se ha configurado como una actividad educativa y transmisora de valores. Conocerlas y estudiarlas nos acerca la historia, nos permite estudiarla, apreciarla mucho más y en parte tocarla.

A lo largo de estos últimos años ha surgido un creciente interés por la iconografía, como instrumento para la investigación histórica de la profesión enfermera y de los fenómenos cuidadores. Autores como Santo Tomás (1996,1997) o Núñez del Castillo (2004,2008) sostienen que los signos iconográficos han de ser considerados como fuentes válidas para avanzar en el conocimiento histórico de la profesión. Siles (1999) en el mismo sentido, señala que cualquier tema, objeto o personaje relacionado con la enfermería en cualquiera de sus épocas y variantes puede ser estudiado iconográficamente. Para el profesor Siles (2011) el análisis iconográfico es una forma de análisis de contenido, que tiene identidad propia y que puede considerarse tanto como una fuente como un método de indudable valor para la historia de la enfermería.

En estás últimas dos décadas han sido elaborados trabajos de especial interés que utilizando la iconografía analizan aspectos concretos de las funciones de enfermería referidos a los cuidados y a la relación de ayuda (Nuñez del Castillo 2004, 2008), o de una forma más específica la imagen de la enfermería y los cuidados a través del cine (Siles, 1994 y 2009), las emisiones filatélicas (Ballesteros, 2006; Guerra, 2008; Luna, Miralles, 2008), la pintura (Calvo, 1994), o los monumentos (Ávila, 2014, Casas y Miralles, 2001; Miralles y Duran, 2005). Por el contrario, la presencia de artículos que hagan referencia a la imagen de la enfermería o de los cuidados a través de las monedas es inexistente, laguna que pretende cubrir la elaboración del presente artículo. 
La lactancia es un fenómeno biocultural de la humanidad, gracias al cual se transmiten amor, alimento, defensas, ternura, comunicación y sabiduría de generación en generación. Esa mezcla de sabiduría y cultura ha suscitado el interés de artistas lo que ha hecho que el tema de la lactancia se repita una y otra vez a lo largo de la historia del arte. En todas las épocas y culturas aparecen representaciones de mujeres amamantando a sus hijos. Estos iconos son una forma de rendir culto a la figura de madre y mujer, portadora y dadora de vida. Este fenómeno tampoco ha sido ajeno a la numismática. No podemos olvidar la enorme cantidad de monedas que se acuñaron ya en época del imperio romano con la representación de la loba amamantado a los fundadores mitológicos de Roma, ni las monedas en la que se representaba a la diosa Isis amamantado a Horus o a reyes y faraones, prueba de que en el antiguo Egipto la lactancia estaba muy bien considerada.

\section{OBJETIVOS}

- Catalogar y describir las monedas contemporáneas más representativas con motivos relacionadas con la práctica de la lactancia materna emitidas desde 1900 hasta el año 2013.

- Mostrar como la numismática se erige en una original y alternativa fuente de información para el estudio y construcción de la historia de los cuidados y de la enfermería.

\section{METODOLOGÍA}

Para la realización del presente estudio descriptivo, de observación documental, se analizaron catálogos de monedas contemporáneas, principalmente el catálogo Krause World-Coins y el catalogo Colnect. Éste último es un sitio web que contiene catálogos de artículos coleccionables el cual permite a sus usuarios agregar ítems y/o editar los mismos. Se completó la búsqueda a través de búsqueda intuitiva en Google. Se realizó así mismo, una búsqueda bibliográfica en las bases de datos CUIDEN, pero los artículos encontrados fueron nulos.

Criterios de inclusión: monedas de curso legal y monedas en prueba de cualquier país en la que aparezcan la imagen de una mujer amamantando, emitidas desde el año 1900 al 2013.

Criterios de exclusión. Monedas que representen a animales amamantando a sus crías o monedas que reflejen a madres con sus hijos en actitud maternal como la mirada, el porteo o el juego. Se excluyen de la búsqueda las monedas emitidas en fechas anteriores al año 1900.

Se encontraron un total de 13 monedas que cumplen con los criterios de inclusión. Se catalogan en base al año de emisión, país emisor, valor, metal, dimensiones y se realiza la descripción de las mismas aplicando la metodología iconográfica.

\section{RESULTADOS}

\section{Año de Emisión: 1921}

País: Estado de Sajonia (Alemania)

Valor: 20 Marcos

Material: Porcelana

Dimensiones: $32 \mathrm{~mm}$

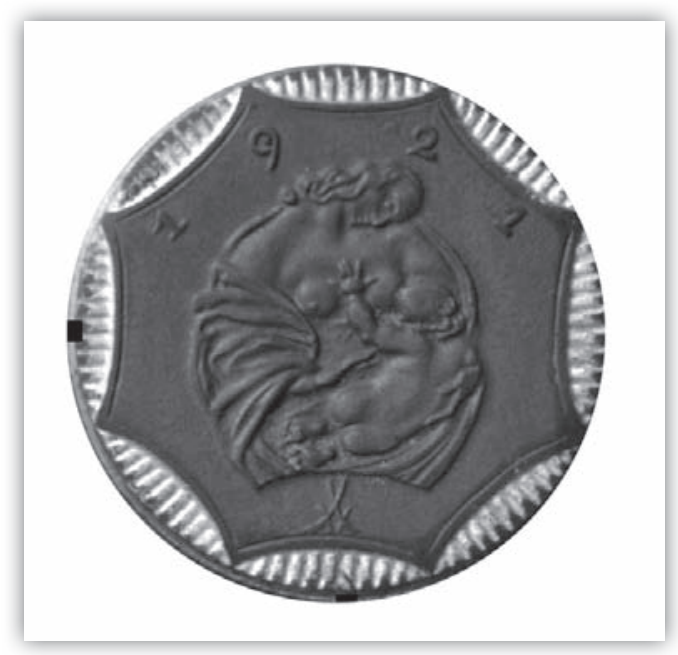


Esta moneda corresponde a una emisión del estado alemán de Sajonia, en la que se representa una bella madre amamantado a su hijo. La lactancia materna asegura la continuación de un vínculo único entre madre e hijo, tan importante en el desarrollo de la persona como el alimento mismo. Tiene la particularidad de ser de porcelana. Debido a la escasez y alto coste de los metales en la Alemania de la década de los años 20, circularon monedas de porcelana fina o gres marrón. Pese a que fueron monedas muy populares por su originalidad, variedad y belleza, la realidad se impuso y se dejaron de utilizar por su escasa resistencia física. Eran monedas que se dañaban, cuando no rompían, con demasiada frecuencia.

\section{Año de Emisión: 1937}

País: Italia

Valor: 5 Liras

Material: Plata

Dimensiones: 23,5 mm

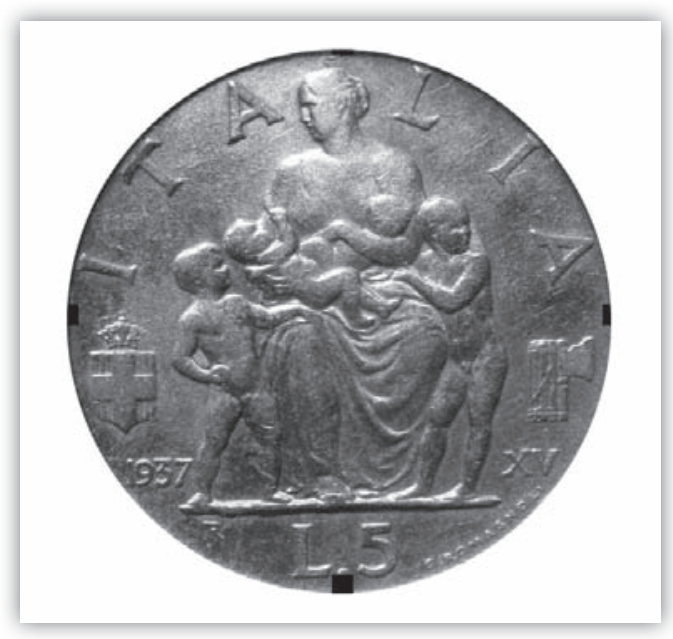

En esta moneda podemos ver a una madre sentada dando de mamar a dos de sus hijos acompañada de otros dos hijos a sus pies. Se trata de una representación alegórica de la fecundidad, imagen que a veces se puede confundir como veremos más adelante con la alegoría de la caridad cristiana. En la antigua Roma la fecundidad solía ser representada con cetro y/o acompañada de uno o varios niños.

\section{Año de Emisión: 1948}

País: Ciudad del Vaticano

Valor: 10 Liras

Material: Aluminio

Dimensiones: $29 \mathrm{~mm}$

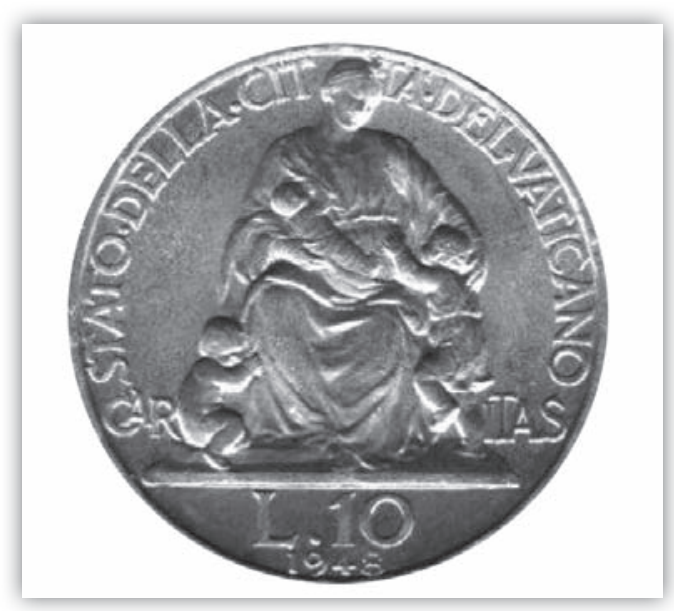

Representación de la alegoría de la caridad cristiana, en la figura de una mujer lactante que da el pecho a hijos de otras madres y de distintas edades. Al pie de la moneda podemos leer dividida la palabra latina "Caritas". La alegoría de la caridad es un tema habitual en el iconografía cristiana, interpretado como un ejemplo de cómo la Iglesia da su alimento espiritual a las almas hambrientas con un alimento espiritual que sólo darían los sacramentos.

\section{Año de Emisión: 1963}

País: Ciudad del Vaticano

Valor: 20 Liras

Material: Bronce

Dimensiones: 21,3 mm 


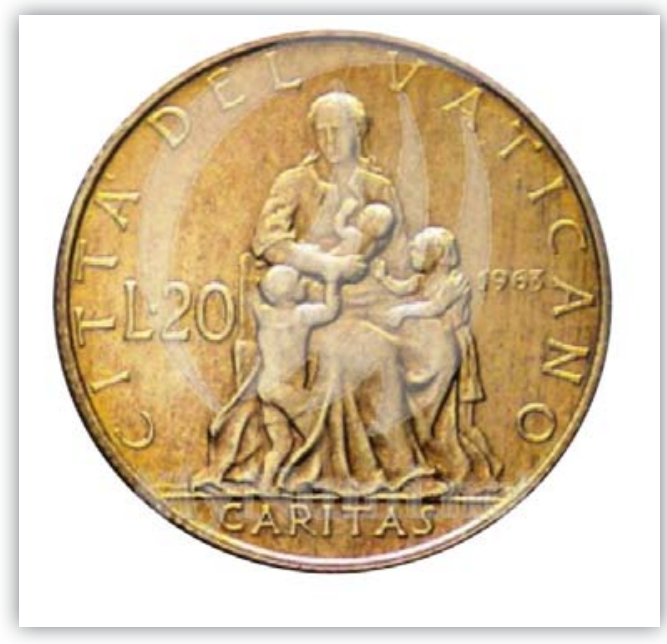

Moneda del pontificado del papa Pablo VI que representa nuevamente la alegoría de la caridad cristiana. Esta moneda repite la tradicional iconografía de esta virtud teologal, mujer sentada amamantando y con niños de distintas edades que la acompañan en su regazo . A los pies de la moneda aparece claramente la inscripción "Caritas".

\section{Año de Emisión: 1971}

País: Polonia

Valor: 10 Zlotych

Material: níquel

Dimensiones: $22 \mathrm{~mm}$

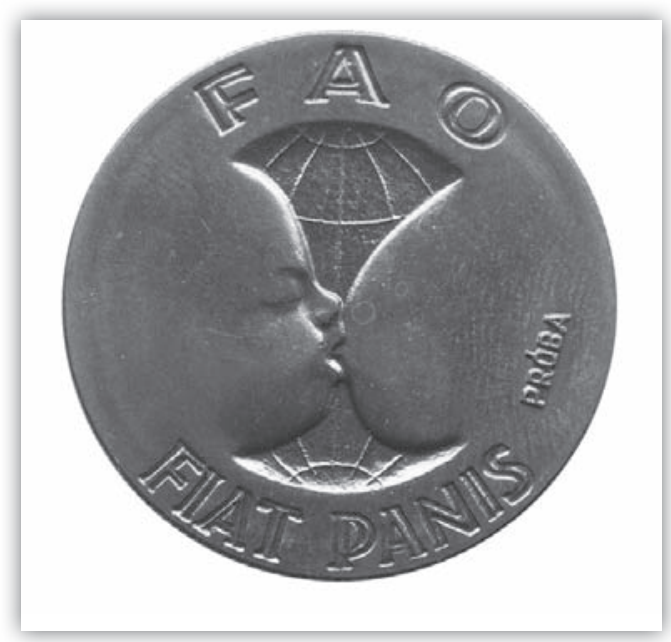

Aunque se trate de una emisión en prueba, es decir, que no llegara a circular, ésta pieza sea quizás esta una de las que de una forma más bella represente la práctica de lactancia materna, por la simpleza de la imagen que contiene, la cabeza de un bebé tomando leche de una enorme mama con el fondo de un globo terráqueo. Nos transmite el mensaje de que la lactancia materna es un factor fundamental para resolver los problemas de hambre en el mundo. Esta moneda estaba destinada a ser una de las correspondientes a un plan numismático promovido por la FAO (Organización de las Naciones Unidas para la Alimentación y la Agricultura) que en el año 1966 invitó a los gobiernos miembros de la organización a que emitiesen monedas con alusiones a los problemas alimentarios. En la parte inferior se puede leer la frase latina "FIAT PANIS" cuyo significado es "Hágase el pan”, lema de la FAO.

\section{Año de Emisión: 1975}

País: Egipto

Valor: 10 piastras

Material: cobre-níquel

Dimensiones: $27 \mathrm{~mm}$

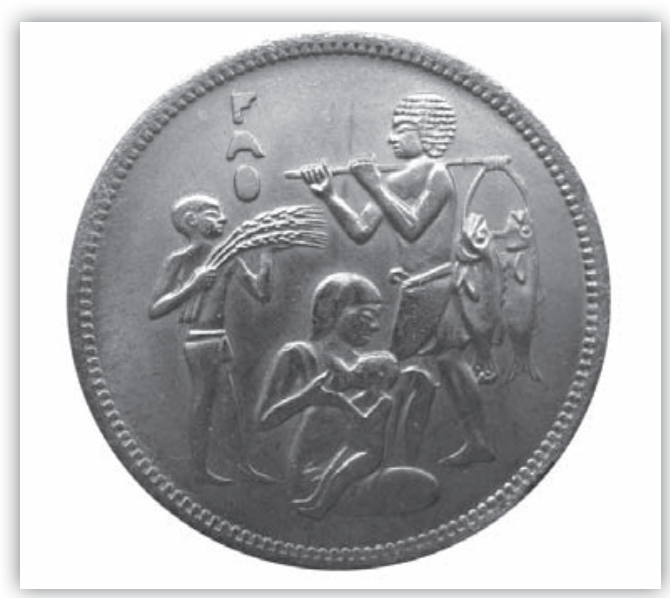

Se trata de otra moneda del plan numismático de la FAO, alusiva a la alimentación. Siguiendo la tradicional iconografía egipcia en la 
que aparecen las figuras de perfil se reproduce una escena familiar en la que vemos a un padre portando peces, a un hijo con espigas de trigo mientras que la madre se dedica a amamantar al hijo pequeño. En la parte superior izquierda las siglas FAO.

\section{Año de Emisión: 1976}

País: Turquía

Valor: 5 liras

Material: Acero

Dimensiones: $32,7 \mathrm{~mm}$

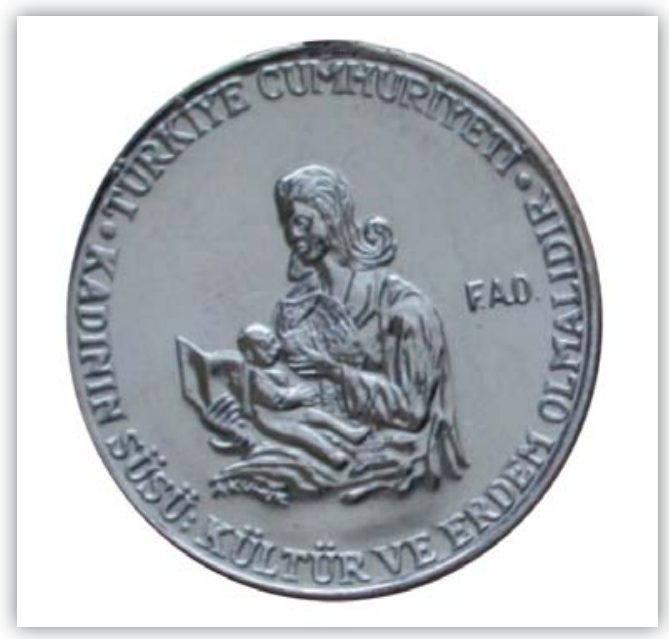

Nuevamente otra moneda del plan numismático de la FAO, donde se observa la particularidad de que la mujer amamanta a su hijo mientras lee un libro. En la parte inferior se lee el lema en idioma turco "“.Kadinin süsü kültür ve erdem olmaldir" que traducido significa "La cultura y la virtud deben adornar a una mujer". A la derecha aparece la inscripción "F.A.O."

\section{Año de Emisión: 1979}

País: Nuevas Hébridas (actual Vanuatu)

Valor: 500 francos

Material: cobre-níquel-aluminio

Dimensiones: $40 \mathrm{~mm}$

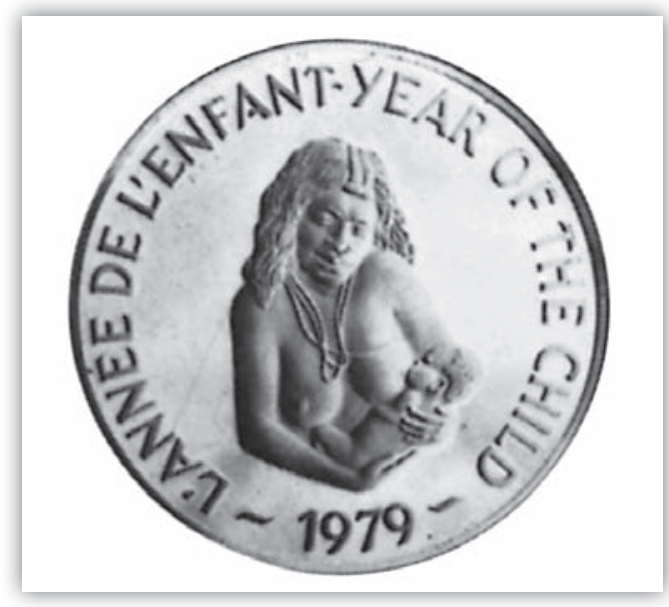

El año 1979 fue elegido por la OMSUNICEF como Año Internacional de la Infancia. La moneda es una emisión en prueba y conmemorativa para dicho evento de Vanuatu, pequeño país del continente oceánico. Se acuñaron una cantidad muy pequeña de esta moneda, tan sólo 60 unidades. Para velar por la salud de los niños se promociona la lactancia representada como una mujer aborigen amamantando a su hijo. Se puede leer el lema Año de la Infancia, en idioma francés e inglés.

\section{Año de Emisión: 1979}

País: Egipto

Valor: 1 libra

Material: plata

Dimensiones: $30 \mathrm{~mm}$

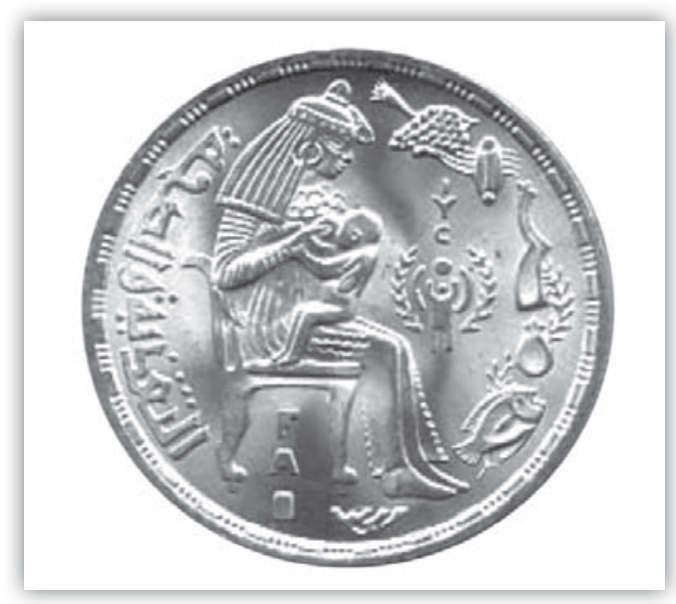


Emisión de Egipto del año 1979 destinada a conmemorar el Año Internacional de la Infancia. A la derecha de la moneda observamos una serie de alimentos (pez, dátil, racimo de uvas,...) y en el centro el primero de los alimentos la leche materna, que aparece representada por la imagen de la diosa Isis amamantando a su hijo Horus. El culto a Isis "Diosa Madre", se extendió por el mundo romano hasta el siglo VI d.C. La imagen de Isis amamantando a Horus acabó asimilada por el cristianismo en la forma de María como Virgen lactante En la moneda podemos observar el logotipo de Unicef, las siglas IYC (Internacional Year Child, Año internacional de la Infancia en idioma inglés). En la parte inferior de la moneda aparece las siglas de la F.A.O, al tratarse además de una nueva emisión del plan numismático F.A.O de este país. A la izquierda de la diosa, en árabe se inscribe el lema "Alimentación y Salud".

\section{Año de Emisión: 1982}

País: Ciudad del Vaticano

Valor: 50 liras

Material: acero

Dimensiones: $24,8 \mathrm{~mm}$

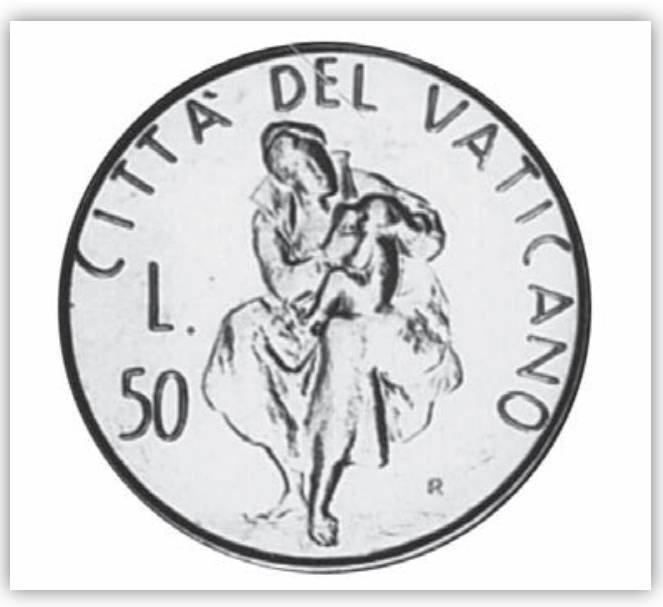

El año 1982 el estado Vaticano dedicó su serie numismática a la familia. La moneda de
50 liras representa de una forma muy sencilla la imagen de una madre amantando a su hijo. La lactancia crea un vínculo de maravillosas posibilidades entre madre e hijo, una relación de amor, de enriquecimiento mutuo, porque es un canal de diálogo entre ambos.

\section{Año de Emisión: 1982}

País: Ciudad del Vaticano

Valor: 100 liras

Material: acero

Dimensiones: $28 \mathrm{~mm}$

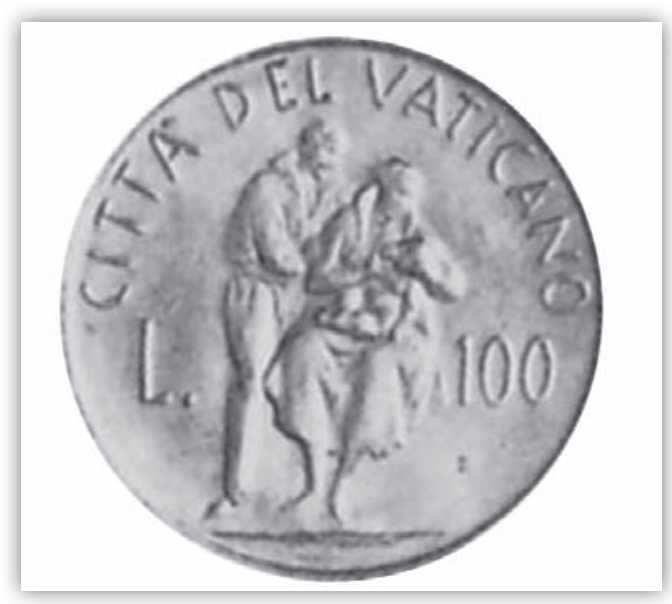

Dentro de la misma serie numismática del vaticano del año 1982 a la que nos referíamos anteriormente se acuñó esta moneda de 100 liras en la que junto a la madre amamantando a su hijo aparece la figura del padre. Tradicionalmente la crianza ha sido principalmente competencia de las madres, mientras que los padres se encargaban de abastecer de alimentos a la familia. Esta moneda da una pincelada sobre el importante papel del padre en la lactancia materna, alejando los caducos estereotipos que lo sitúan fuera de todo lo relacionado con ella. Muestra el muy importante espacio que debe ocupar el padre como soporte junto a la madre y el lactante. El ser padre-soporte es algo que los padres no deberían dejar pasar y 
es una experiencia muy enriquecedora y placentera tanto a nivel individual, para todos sus miembros, como a nivel familiar.

\section{Año de Emisión: 1985}

País: Polonia

Valor: 100 zlotych

Material: acero niquelado

Dimensiones: 29,5 mm

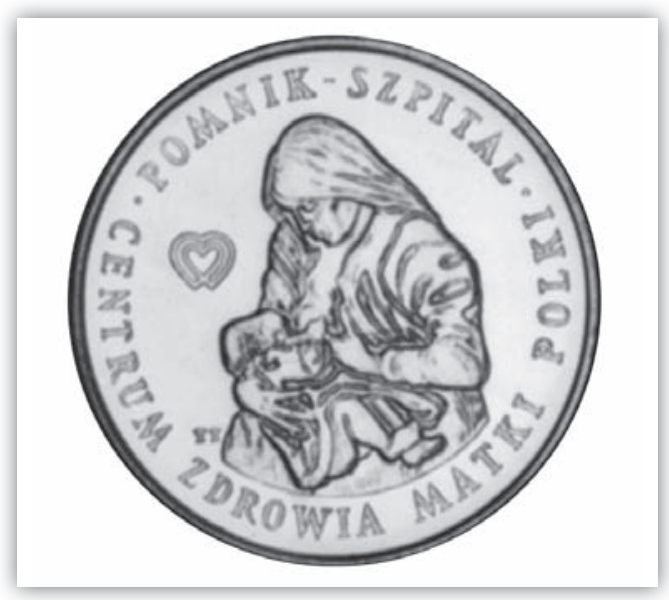

Moneda que conmemora el centenario de un hospital de mujeres polaco. En la imagen podemos ver representada una maternidad, obra del artista polaco Stanislaw Wyspiansky (1869-1907) pintada al pastel en 1902 que representa a la mujer e hija del artista. Esta obra se ha representado también en sellos polacos de los años 1959 y 1969. Alrededor de la imagen puede leerse "Centrum zdrowia matki polki", traducido al español "Centro de salud madre polaca" y "Pomnik szpital", traducido al español "Monumento Hospital".

\section{Año de Emisión: 1992}

País: Ciudad del Vaticano

Valor: 200 liras

Material: Aluminio-bronce

Dimensiones: $24 \mathrm{~mm}$

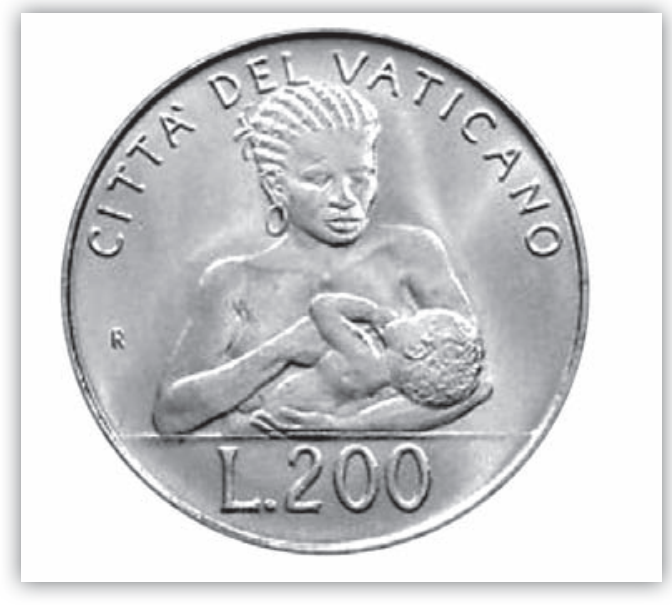

Moneda conmemorativa del $14^{\circ}$ año de pontificado de Juan Pablo II. Se eligió la figura de una mujer africana amamantando a su hijo en alusión a su viaje a países africanos en el año 1992.

\section{CONCLUSIONES}

Hay que esperar hasta el año 1921 en el estado alemán de Sajonia para encontrar la primera moneda contemporánea con una imagen donde es posible visualizar la práctica de la lactancia materna. Desde entonces hasta nuestros días tan sólo se han acuñado 13 monedas alusivas a esta práctica, de 7 países diferentes. Entre los países más prolíficos destacan Cuidad del Vaticano, Egipto y Polonia. En esta pequeña colección temática podemos encontrar monedas en prueba que nunca llegaron a circular, monedas circulantes de escaso valor nominal, ejemplares conmemorativos de alto valor facial y una gran diversidad de metales y tamaños. El motivo de representar en una moneda a una madre lactante apenas obedece en ocasiones a un reconocimiento expreso al fomento de dicha práctica, sino más bien han sido utilizadas para representar o simbolizar motivos tan variopintos como la virtud cristiana de la caridad o la fecundidad, 
para aludir a los problemas alimentarios en el mundo, o como motivo para conmemorar un evento concreto, como por ejemplo el año internacional de la infancia o el centenario de un hospital maternal. A pesar de esta falta de reconocimiento formal, debido a la importancia difusora y propagandística de las monedas, a su uso común en la vida cotidiana y a ser valiosas entre la población, la aparición de la escena de una mujer lactante en ellas sirve para promocionar aunque sea de una forma indirecta la práctica de lactancia materna.

Las monedas se comportan como una interesante y original fuente alternativa de estudio, aún por descubrir en su totalidad, para la construcción de la Historia de los Cuidados y de la Enfermería. Se hace por tanto necesario continuar identificando, describiendo y contextualizando fenómenos cuidadores en las emisiones numismáticas,

\section{BIBLIOGRAFÍA}

- Ávila Olivares, J.A. (2014). Los signos iconográficos del reconocimiento público de la enfermería en España: su importancia y significación. Cultura de los cuidados (Edición digital), 18, 38. Disponible en <http://dx.doi. org/10.7184/cuid2014.3812> consultado el 20 de agosto de 2014

- Ballesteros Álvaro, A.M. (2006). La Enfermería española y su historia en la filatelia. Temperamentum,4, Disponible en http://indexf.com/temperamentum/tn4/t6245.php> consultado el 14 de agosto de 20014.

- Calvo Calvo, M.A. (1994). Análisis iconográfico de la pintura de Lucas Valdés "Asistencia a los sacerdotes en la enfermería”. Híades, 10, 403-412.

- Casas, M. F. y Miralles, M.T. (2001). Monumento a las enfermeras de la Cruz roja de Astorga. Enfermería clínica, (4), 161-165

- RAEL (2001). Diccionario de la Lengua Española (DRAEL) (22. a edición), Real Academia Española, Madrid: Espasa.
- Guerra González, J.E. (2008).Historia de la enfermería. Reflejo de la Filatelia. Híades, 10, 782-803.

- Luna Gálvez, S. (2004). La Enfermería en la filatelia. Hades,9, 465-499.

- Miralles Sangro, M. T. (2008). La Enfermería a través de los sellos. Madrid: Ediciones DAE.

- Miralles, M.T. y Duran, M. (2005). La enfermera en el monumento madrileño (1908-1936). Index de Enfermería,51, 65-69.

- Núñez del Castillo, M. y Siles González, J. (2004). Evolución de los cuidados enfermeros. Análisis iconográfico desde la perspectiva de Virginia Henderson. Cultura de los cuidados, 8(15), 17-25.

- Núñez del Castillo, M., Siles González, J., Jurado Moyano, I. (2008). Relación de ayuda a través de la historia: una aportación desde la perspectiva iconográfica. Cultura de los Cuidados, 12 (23): 27-34.

- Santo Tomás, M. et al. (1996). Iconografía y enfermería: un instrumento para la investigación histórica. Index de enfermería, (16-17), 87-88.

- Santo Tomás M. et al. (1997). Iconografía y Enfermería.. Un instrumento para la investigación histórica. Index de Enfermería,19, 13-16.

- Siles González, J. et al. (1994 b) La enfermería a través del cine: un estudio histórico y transcultural. Híades, 10, 761780.

- Siles González, J. (1999). Historia de la Enfermería. Alicante: Aguaclara, 75-76.

- Siles González, J. (2009). Origen de la Enfermería en el cine: El género histórico-documental y bibliográfico. Cuaderns de Cine,4, 57-69.

- Siles González, J. (2011). Historia de la Enfermería. Madrid: Difusión de Avances de Enfermería (DAE, SL), 95. 